\title{
The mechanisms involved in formation of deletions and duplications of 15q11-q13
}

\author{
W P Robinson, F Dutly, R D Nicholls, F Bernasconi, M Peñaherrera, R C Michaelis, \\ D Abeliovich, A A Schinzel
}

Department of

Medical Genetics, University of British

Columbia, Vancouver, Canada

W P Robinson

F Bernasconi

M Peñaherrera

Institut für

Medizinische Genetik

der Universität Zürich,

Switzerland

F Dutly

A A Schinzel

Department of

Genetics, Case

Western Reserve

University School of

Medicine and Center

for Human Genetics

and University

Hospital of Cleveland,

Cleveland, USA

R D Nicholls

Greenwood Genetic Center, Greenwood, USA

R C Michaelis

Hadassah Hebrew University Hospital, Jerusalem, Israel D Abeliovich

Correspondence to: Dr Robinson, BC Research Institute for Child and Family Health, Room 170-950, West 28th Avenue, Vancouver, BC, Canada V5Z $4 \mathrm{H} 4$

Received 8 July 1997

Revised version accepted for publication 15 August 1997

\section{Abstract}

Haplotype analysis was undertaken in 20 cases of 15q11-q13 deletion associated with Prader-Willi syndrome (PWS) or Angelman syndrome (AS) to determine if these deletions arose through unequal meiotic crossing over between homologous chromosomes. Of these, six cases of PWS and three of AS were informative for markers on both sides of the deletion. For four of six cases of paternal 15q11-q13 deletion (PWS), markers on both sides of the deletion breakpoints were inferred to be of the same grandparental origin, implying an intrachromosomal origin of the deletion. Although the remaining two PWS cases showed evidence of crossing over between markers flanking the deletion, this was not more frequent than expected by chance given the genetic distance between proximal and distal markers. It is therefore possible that all PWS deletions were intrachromosomal in origin with the deletion event occurring after normal meiosis I recombination. Alternatively, both sister chromatid and homologous chromosome unequal exchange during meiosis may contribute to these deletions. In contrast, all three cases of maternal 15q11-q13 deletion (AS) were associated with crossing over between flanking markers, which suggests significantly more recombination than expected by chance $(p=0.002)$. Therefore, there appears to be more than one mechanism which may lead to PWS/AS deletions or the resolution of recombination intermediates may differ depending on the parental origin of the deletion. Furthermore, 13 of 15 cases of 15q11-q13 duplication, triplication, or inversion duplication had a distal duplication breakpoint which differed from the common distal deletion breakpoint. The presence of at least four distal breakpoint sites in duplications indicates that the mechanisms of rearrangement may be complex and multiple repeat sequences may be involved.

$(\Im$ Med Genet 1998;35:130-136)

Keywords: Prader-Willi syndrome; Angelman syndrome; deletion; duplication 15q11-q13

Both Prader-Willi syndrome (PWS) and Angelman syndrome (AS) result from large interstitial deletions of chromosome 15q11-q13 in $70-75 \%$ of cases. ${ }^{1-4}$ PWS results when the deletion occurs on the paternal chromosome and
AS when the same deletion is on the maternal chromosome. ${ }^{5}$ Both syndromes occur at a frequency of about $1 / 15000-1 / 20000^{6-8}$ and therefore maternal and paternal deletions each occur in approximately $1 / 20000-1 / 28000$ livebirths.

Although there are a few exceptions observed, the vast majority of both maternal and paternal deletions of this region are of similar size $(\sim 4 \mathrm{Mb})$ and have tightly clustered breakpoints. ${ }^{5-11}$ There are two common proximal breakpoints with similar frequencies $(-50 \%$ of each) in both maternally and paternally derived deletions. ${ }^{1213}$ It has been suggested that most distal breakpoints are included in the region covered by a single YAC. ${ }^{9}$ The common deletion is much larger than necessary to cause the PWS or AS phenotype, as deletions of less than $7 \mathrm{~kb}$ including the imprinting control centre can also result in the clinically typical PWS or AS phenotype ${ }^{14} 15$ (unpublished results). The frequent occurrence and high clustering of breakpoints in the large deletions imply an instability at these sites. It is commonly suggested that microdeletions arise through mispairing of large duplicated sequences. Repetitive DNA is abundant in the human genome, but the frequency and distribution of microdeletions does not seem to be random with regard to these sequences. Additional factors are therefore necessary to explain why certain regions of the genome are predisposed to frequent mispairing and deletion. ${ }^{16}$ In addition, these breakpoints are not sites of high homologous recombination and cannot therefore be explained simply by a tendency to double strand breaks at these sites during meiosis $\mathrm{I}^{17}{ }^{18}$

Interstitial duplications ${ }^{19-21}$ and triplications $^{22-24}$ of the PWS/AS region have also been reported. In most of these cases, maternal heterozygosity of duplicated genes is observed, indicating involvement of two different maternal chromosomes. It is therefore of interest to determine if these duplications/ triplications are the result of a mechanism related to deletion events. A meiotic unequal crossover between homologous chromosomes is expected to result in the formation of reciprocal duplication and deletion products, which show recombination of flanking markers (fig 1A). Such a mechanism has been reported to be involved in duplications of $17 \mathrm{p} 11.2-\mathrm{p} 12$, associated with Charcot-Marie Tooth disease IA (CMT1A), and deletions of the same region which are associated with hereditary neuropathy with liability to pressure palsies (HNPP) ${ }^{25}{ }^{26}$ In contrast, an intrachromosomal 

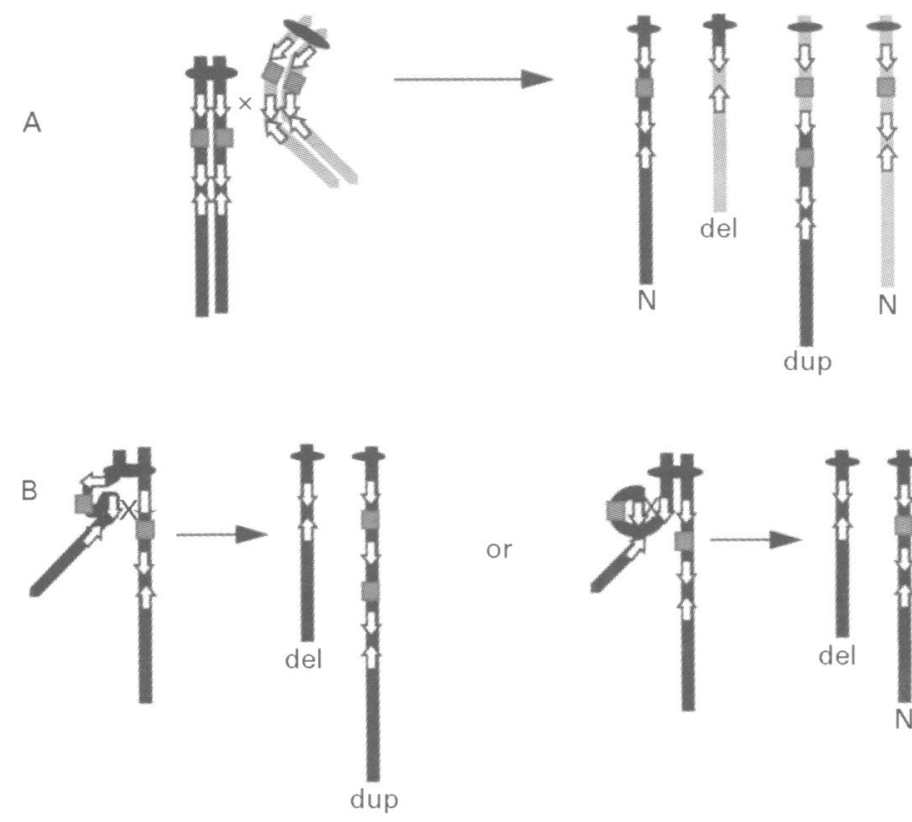

or

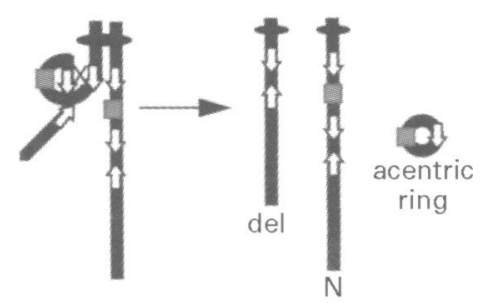

C
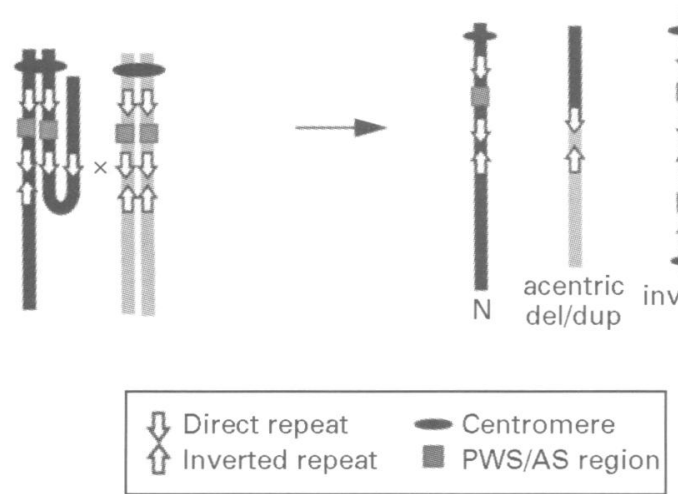

Figure 1 Models of rearrangements in chromosome 15q11-q13. (A) Classical model of unequal crossing over leading to reciprocal duplication (dup) and deletion (del) with recombination of flanking markers. (B) Unequal sister chromatid exchange (left) or intrachromatid (right) recombination may lead to deletion with no recombination of flanking markers. (C) Recombination between inverted repeats leading to inversion duplication (inv dup) derived from two different chromosomes. The presence of multiple direct and inverted repeats can lead to variable breakpoints; those shown are for illustrative purposes.

event will not result in recombination of flanking markers and should not be associated with a reciprocal duplication product, unless the crossing over is between sister chromatids (fig 1B). Interestingly, in one case of HNPP with maternal origin, the deletion was determined to be intrachromosomal by haplotype reconstruction using data from the grandparents, ${ }^{27}$ and it was suggested that the intrachromosomal events may be specific to female meioses. In addition, the rarity of CMT1A duplications of maternal origin is not explained by a lower level of female than male meiotic recombination in this region. ${ }^{28}$ The sex specific difference was suggested to be a result of male specific factors which help to form or stabilise the duplicated chromosome. ${ }^{29}$ A mariner transposon-like element within the repeat has been suggested to be involved in mediating these recombination events. ${ }^{30}$

The 15q11-q13 region is also notable for the frequent occurrence of inversion duplications. Previous reports indicate that "small" supernumerary isodicentric inversion duplication $15 q$ (inv dup 15) chromosomes share breakpoints in common with the two common proximal PWS/AS deletion breakpoints, while "large" inv dup 15 chromosomes tend to be of two sizes with only one breakpoint similar to the distal deletion breakpoint. ${ }^{31-33}$ The formation of isodicentric chromosomes may also involve recombination between inverted repeats as shown in fig 1C. However, alternative mechanisms include a "U type" exchange, ${ }^{34}$ or repair of a broken chromosome through replication and end to end fusion. Although the proposed mechanisms differ, the similarity of breakpoints between inversion duplications and deletions of this region, as well as the observation of patients carrying both a small isodicentric 15 plus a 15 q11-q13 deletion ${ }^{35}$ or duplication, ${ }^{21}$ suggests that at least some of the causes may be related.

In order to determine if PWS/AS deletions are associated with meiotic recombination between flanking markers and hence if deletions are likely to be intra- or interchromosomal events, marker haplotypes were analysed in 20 families. Grandparental DNA was available in 18 of these, and haplotypes were inferred in the two additional families using unaffected sibs. The results exclude an unequal crossover between homologous chromosomes at meiosis as the deletion mechanism in four of six informative PWS cases. However, all three informative AS deletion cases were associated with a crossover event. A comparison of proximal and distal breakpoints between common deletions and duplications (or triplications and inversion duplications) of this same region indicates that the observed maternal duplications of this region are not the reciprocal products of deletion events, or at least that the breakpoints are much more variable. It is hypothesised that multiple mechanisms for rearrangement in this region exist and may involve unequal sister chromatid exchange or intrachromatid recombination either during or after meiosis in at least a portion of cases. The greater number of breakpoint sites associated with inversion duplications than deletions may also reflect relative location of inverted versus direct repeat sequences.

\section{Methods \\ PATIENTS}

Patients with 15q11-q13 deletions were ascertained through routine molecular investigations of PWS and AS patients. Deletions were diagnosed by virtue of lack of maternal or paternal inheritance of the commonly deleted RFLP probes and dosage analysis ${ }^{36}$ or, usually, by microsatellite analysis. ${ }^{20}$ Because there are no published markers more proximal than D15S1035, D15S541, D15S542, and D15S18 (order of these four polymorphisms is not known), and as these markers are deleted in half the patients, ${ }^{13}$ only patients with the smaller deletion will be informative in this analysis (for recent mapping data in this region see Robinson et $a l^{3}$ ). In addition, many patients were uninformative even if they were intact for these markers if the parent in 
Table 1 Summary of inheritance in informative PWS deletion cases

\begin{tabular}{lllllll}
\hline & \multicolumn{2}{l}{ Closest non-deleted informative marker } & & & \\
\cline { 2 - 5 } & Proximal & Inheritance & Distal & Inheritance & Intermarker \\
distance (cM) & Crossover \\
\hline PWS-47 & D15S541 & Grandmaternal & D15S144 & Grandmaternal & 23 & No \\
PWS-RN & D15S18 & Grandmaternal & D15S24 & Grandmaternal & 17 & No \\
PWS-99* & D15S541 & Grandparent A & D15S165 & Grandparent B & 17 & Yes \\
PWS-178 & D15S542 & Grandpaternal & D15S118 & Grandpaternal & 27 & No \\
PWS-235 & D15S1035 & Grandpaternal & ACTC & Grandpaternal & 26 & No \\
PWS-340 & D15S1035 & Grandpaternal & D15S165 & Grandmaternal & 17 & Yes \\
\hline
\end{tabular}

$p=0.37$ to observe two or more crossovers by chance from these six meioses.

${ }^{\star}$ Grandparental haplotypes inferred from sibs and cannot be designated grandmaternal or grandpaternal.

†Two additional cases with grandparents were informative distally but not for any proximal marker; one showed grandpaternal inheritance at D15S165 and one grandmaternal inheritance at D15S118.

Table 2 Summary of inheritance in informative AS deletion cases

\begin{tabular}{lllllll}
\hline & \multicolumn{3}{l}{ Closest non-deleted informative marker } & & & Intermarker \\
& \cline { 2 - 5 } & Proximal & Inheritance & Distal & Inheritance & Crossover \\
\hline AS-V3 & D15S542 & Grandpaternal & D15S1048 & Grandmaternal & 13 & Yes \\
AS-V14 & D15S542 & Grandmaternal & D15S1048 & Grandpaternal & 13 & Yes \\
AS-193 & D15S542 & Grandmaternal & D15S165 & Grandpaternal & 13 & Yes \\
\hline
\end{tabular}

$\mathrm{p}=0.002$ to observe $3 / 3$ crossovers by chance.

* Seven additional cases with grandparents were informative distally but either uninformative or deleted for proximal markers; of these, five showed grandpaternal and two grandmaternal inheritance for markers flanking the distal deletion breakpoint.

question was homozygous at these loci. In one case (PW-99), grandparents were not available but haplotypes were inferred from two sibs.

Normal maternal and paternal inheritance of microsatellite markers was observed outside the deleted region, thus excluding uniparental disomy in all cases. PWS-47 is identical to patient PWS-47 previously reported.' PWS-RN was previously published as HS2. ${ }^{37}$ Cytogenetic analysis in all cases indicated that the deletions were interstitial and not associated with a translocation or other chromosomal rearrangement. In addition, the fact that proximal loci were intact excludes a deletion arising from an unbalanced cryptic translocation.

DNA ANALYSIS

Isolation of genomic DNA from peripheral blood, restriction enzyme analysis, electrophoresis, and Southern blotting were performed using standard procedures as described previously. $^{36}{ }^{37}$ Probes used include pIR39 (D15S18), IR4-3R (D15S11), p3-21 (D15S10), and pCMW-1 (D15S24). PCR amplification of microsatellite loci was performed using standard conditions (usually $55^{\circ} \mathrm{C}$ annealing temperature). A total of $0.5-3 \mu \mathrm{l}$ of reagent was then mixed with an equal volume of urea loading buffer ( $42 \%$ urea, $0.1 \%$ xylene cyanol, $0.1 \%$ bromphenol blue, and $0.1 \%$ of 0.5 $\mathrm{mol} / \mathrm{l}$ EDTA) and directly loaded onto a 0.4 $\mathrm{mm}$ thick $6 \%$ polyacrylamide $/ 50 \%$ urea gel. Visualisation of bands was done by silver staining of the gels. Information on microsatellite loci tested can be obtained from the Genome Data Base. All primers were obtained from Research Genetics Inc (Huntsville, AL).

The probe IR39 (D15S18) maps proximal to the common PWS/AS deletion in about $50 \%$ of patients $^{12}$ (unpublished data). Similarly, the microsatellite loci D15S541 and D15S542, which map to a YAC containing D15S18, are deleted in roughly half of PWS or AS patients. ${ }^{13}$ The deleted region is about $4 \mathrm{Mb}^{9}$ and covers more than $10 \mathrm{cM} \cdot{ }^{18} \mathrm{D} 15 \mathrm{~S} 11$ is located within the commonly deleted region. The probe CMW-1, detecting the D15S24 locus, maps outside (distal to) the deletion region in almost all patients ${ }^{13}$ (R D Nicholls, M Mascari unpublished data). D15S165 maps distal to D15S24 (R D Nicholls, unpublished results) and less than $5 \mathrm{cM}$ from the distal breakpoint. D15S1048 has also been localised near to D15S165 based on recombination in CEPH

Table 3 Extent of duplication in one tandem duplication, two interstitial triplications, and 12 inv dup15q11-q13 cases. The genetic distance of each marker in cM from D15S541 is indicated

\begin{tabular}{|c|c|c|c|c|c|c|c|c|c|c|c|c|c|c|c|c|}
\hline & & \multicolumn{15}{|l|}{ Patient } \\
\hline & & Dup4 & Trip1 & Trip2 & ID10 & ID211 & ID149 & ID189 & ID7 & ID107 & $I D 90$ & ID151 & ID104 & ID190 & ID215 & $I D 188$ \\
\hline $\begin{array}{l}\begin{array}{l}\text { Copies PWS/AS } \\
\text { critical region }\end{array} \\
\text { D15S12t } \\
\text { D15S1019 } \\
\text { D15S1048 } \\
\text { D15S165 } \\
\text { D15S24 } \\
\text { D15S1031 } \\
\text { D15S976 } \\
\text { D15S1043 } \\
\text { D15S1010 } \\
\text { D15S144 }\end{array}$ & $\begin{array}{l}(\mathrm{cM}) \\
\sim 17 \\
20 \\
20 \\
22 \\
\frac{2}{22} \\
23 \\
23 \\
24 \\
27\end{array}$ & $\begin{array}{l}3 \\
\text { nt } \\
\text { ui } \\
\text { ui } \\
\text { dup* } \\
\text { nt } \\
\text { dup } \\
\text { ui } \\
\text { ui } \\
N^{\star} \\
N^{\star}\end{array}$ & $\begin{array}{l}\text { 4 } \\
\text { dup } \\
\text { ui } \\
\text { ui } \\
\text { ui } \\
\text { dup } \\
\text { nt } \\
\text { ui } \\
\text { dup } \\
\text { ui } \\
\text { ui }\end{array}$ & $\begin{array}{l}4 \\
\text { nt } \\
\text { dup } \\
\text { dup } \\
\text { ui } \\
\text { nt } \\
\text { nt } \\
\text { dup } \\
\text { ui } \\
\text { N } \\
\text { N }\end{array}$ & $\begin{array}{l}4 \\
\text { nt } \\
\text { dup } \\
\text { ui } \\
\text { ui } \\
\text { nt } \\
\text { dup } \\
\text { ui } \\
\text { dup } \\
\text { ui } \\
\text { dup }\end{array}$ & $\begin{array}{l}4 \\
\text { nt } \\
\text { nt } \\
\text { ui } \\
\text { dup } \\
\text { ui } \\
\text { dup } \\
\text { nt } \\
\text { dup } \\
\text { dup } \\
\text { ui }\end{array}$ & $\begin{array}{l}4 \\
\text { dup } \\
\text { ui } \\
\text { ui } \\
\text { dup } \\
\text { dup } \\
\text { dup } \\
\text { nt } \\
\text { ui } \\
\text { nt } \\
\text { nt }\end{array}$ & $\begin{array}{l}4 \\
\text { dup } \\
\text { nt } \\
\text { ui } \\
\text { dup } \\
\text { ui } \\
\text { nt } \\
\text { dup } \\
\text { dup } \\
\text { ui } \\
\text { nt }\end{array}$ & $\begin{array}{l}4 \\
\text { nt } \\
\text { nt } \\
\text { ui } \\
\text { ui } \\
\text { nt } \\
\text { ui } \\
\text { dup } \\
\text { dup } \\
N^{\star} \\
\text { nt }\end{array}$ & $\begin{array}{l}4 \\
\text { dup* } \\
\text { ui } \\
\text { dup } \\
\text { dup } \\
\text { dup }^{\star} \\
\text { dup }^{\star} \\
\text { dup } \\
\text { ui } \\
\text { ui } \\
\text { N }\end{array}$ & $\begin{array}{l}4 \\
\text { dup } \\
\text { nt } \\
\text { dup } \\
\text { nt } \\
\text { dup }^{\star} \\
\text { dup }_{\text {ui }} \\
\text { ui } \\
\text { ui } \\
\text { ui }\end{array}$ & $\begin{array}{l}4 \\
\text { dup } \\
\text { nt } \\
\text { ui } \\
\text { dup } \\
\text { dup }^{\star} \\
\text { dup* } \\
\text { nt } \\
\text { ui } \\
\text { n }^{\star} \\
\text { N }\end{array}$ & $\begin{array}{l}4 \\
\text { dup } \\
\mathbf{N}^{\star} \\
\mathbf{N} \\
\mathbf{N} \\
\mathbf{N} \\
\text { ui } \\
\text { ui } \\
\mathbf{N} \\
\text { nt } \\
\text { nt }\end{array}$ & $\begin{array}{l}4 \\
\text { dup } \\
\text { ui } \\
\mathbf{N} \\
\mathbf{N} \\
\mathbf{N} \\
\text { nt } \\
\mathbf{N} \\
\text { ui } \\
\text { ui } \\
\text { nt }\end{array}$ & $\begin{array}{l}4 \\
N^{\star} \\
\text { ui } \\
\mathbf{N} \\
\mathbf{N} \\
\mathbf{N} \\
\text { nt } \\
\text { ui } \\
\text { ui } \\
\text { ui } \\
\text { nt }\end{array}$ & $\begin{array}{l}4 \\
\mathbf{N} \\
\mathbf{N} \\
\text { ui } \\
\mathbf{N} \\
\mathrm{nt} \\
\mathrm{nt} \\
\text { ui } \\
\mathbf{N} \\
\text { ui } \\
\mathrm{nt}\end{array}$ \\
\hline
\end{tabular}

*dup or $\mathrm{N}$ inferred by dosage of alleles only.

†The common deletion breakpoint lies just distal to D15S12.

$\mathrm{nt}=$ not tested; dup (bold) $=$ three distinct alleles were visible.

$\mathrm{N}$ (bold) $=$ only one allele from heterozygous mother was transmitted. 

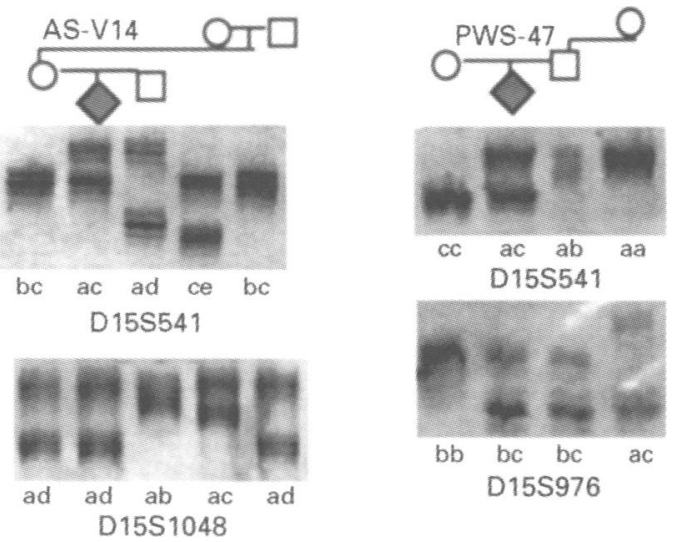

Figure 2 Sample molecular results in deletion cases. AS-V14 has inherited the grandmaternal D15S541 allele and the grandpaternal D15S1048 allele on the maternal haplotype; PWS -47 has inherited the grandmaternal allele on the father's haplotype at both D15S541 and D15S976.

and UPD15 families (W P Robinson, unpublished results). Sex specific genetic distances given in table 1 are taken from CEPH/ Généthon online data and Robinson and Lalande. ${ }^{18} \mathrm{CEPH}$ based genetic locations are given in tables 2 and 3 for additional markers tested in this region.

Microsatellite loci were also used to delineate further the extent of deletions and duplications in this region. Lack of transmission of a paternal or maternal allele in deletion cases was considered evidence that this locus was included in the deletion, whereas heterozygosity in the patient indicated normal biparental inheritance. In cases of duplication, the presence of three distinct alleles was considered conclusive evidence that this locus was included in the duplication, whereas a dosage difference between alleles was considered suggestive of this. Dosage was measured qualitatively by comparing the intensities of bands in parents and controls. At least two independent observers judged dosage. If it was not clear to both observers whether one band was duplicated, the result was recorded as uninformative. Although this method cannot be considered $100 \%$ accurate, it is strongly supportive of the presence or absence of duplication. Lack of inheritance of both maternal alleles and an equal dosage of two alleles present in the patient was taken as definite evidence that this locus was not included in the duplication.
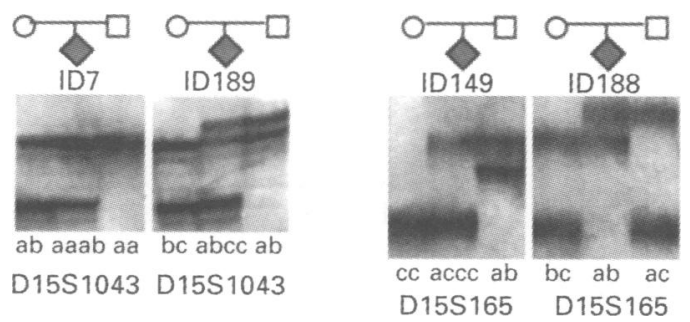

Figure 3 Sample molecular results in inv dup 15 cases. ID7 appears to have a duplication at D15S1043 by dosage only, whereas a duplication of this locus in ID189 is clearly indicated by three distinct alleles. ID149 appears to have a maternal duplication at D15S165 by dosage, whereas ID188 has inherited only one maternal allele in a single dose (as compared to the paternal allele).

\section{Results}

Sample molecular results are given in figs 2 and 3. Haplotype data for all informative families are summarised in table 1 . In four of five informative PWS deletion cases with grandparents available, markers flanking the paternal deletion both proximally (D15S541, D15S542, D15S1035, or D15S18) and distally (D15S144, D15S24, or D15S118) show inheritance from the same grandparent (table 1). In two cases, the flanking markers showed origin from the grandmother and, in the other two cases, the deletion arose on the grandpaternal haplotype. Specifically, there was no evidence of crossing over between the grandmaternal and grandpaternal haplotypes within the deleted region. In contrast, case PWS-340 showed grandpaternal inheritance for D15S1035 but grandmaternal inheritance distal to the deletion breakpoint at D15S165. Thus, a crossover event between two father's chromosomes must have occurred either before or during the deletion event. In the case of PWS-99, the grandparents were not available and haplotypes were inferred from the sibs. Two possibilities exist in this family: either the patient has inherited a recombinant chromosome from the father, or both of the sibs have inherited a paternal recombinant chromosome in this region. Given a male recombination distance of $17 \mathrm{cM}$ between D15S541 and D15S165, the odds are 6:1 in favour of the former (only one rather than two recombinant offspring in this region). Furthermore, as the two normal sibs share the same paternal allele at the proximal marker D15S541 and at GABRB3, the probability of the latter hypothesis is reduced as it would require a recombination specifically between GABRB3 and D15S165 in both sibs. This case has therefore been classified as a probable recombinant.

Even though two cases appear to show a recombination between the markers flanking the deletion, this does not exclude a postmeiosis I intrachromosomal origin in these cases. To calculate the probability of observing chance recombinants from cases presented in table 1, one needs to account for the genetic distance between markers in each informative case. Assuming that the probability of observing recombination between two markers corresponds to genetic distance (that is, $1 \mathrm{cM}=1 \%$ recombination), the probability of not observing any crossovers between the flanking markers in these six cases if in fact normal levels of meiotic recombination precede the deletion event is simply:

$$
\mathrm{p}(0 / 6 \text { recombinant })=\prod_{i=1}^{N}\left(1-\theta_{i}\right),
$$

where $\theta_{i}$ is the recombination fraction between informative flanking markers for case $i$, and $N$ is the total number of cases. Thus, $\mathrm{p}(0 / 6$ recombinant $)=(1-0.23)^{\star}(1-0.17)^{\star}(1-0.17)^{\star}$ $(1-0.27)^{\star}(1-0.26)^{\star}(1-0.17)=0.24$. Similarly, one can consider the probability that one of the six cases would be recombinant: $p(1 / 6$ recombinant $)=0.39$, or that two or more crossovers would be observed: $p(\geqslant 2 / 6$ crossovers $)=1-p$ $(0 / 6$ recombinant $)-p(1 / 6$ recombinant $)=0.37$. Therefore observing two recombinant cases is 
well within the expected number if recombination is completely independent of the deletion event.

The result is different in the case of the three fully informative AS cases carrying maternal deletions of 15q11-q13. The female recombination distance in this region is slightly shorter than in males, and the expected probabilities of observing $0 / 3,1 / 3,2 / 3$, or $3 / 3$ crossovers by chance (as calculated above) in the three cases presented in table 2 are $0.659,0.295,0.044$, and 0.002 , respectively. However, marker results showed different grandparental origin of haplotypes on either side of the deletion breakpoints in all three cases. Thus, for the AS deletions it is unlikely that the recombination events were the result of chance and are not associated with the deletion $(p=0.002)$.

It appears from tables 1 and 2 that there is no significant bias in terms of grandparental origin of the chromosomes involved in the exchange event in either the maternal or paternal deletions. Including additional cases which were informative for distal but not proximal markers, grandpaternal inheritance was seen for markers flanking the deletion distally in three of seven paternal and seven of 10 maternal deletion cases. The lack of bias in involvement of grandparental chromosomes would seem to exclude a mechanism of deletion which specifically occurred before or during resetting of the imprint on one or the other parental chromosome, unless the resetting of a paternal imprint as maternal and vice versa somehow involved exchange or association between homologues as part of the process, as has been previously suggested. ${ }^{38}{ }^{39}$

To refine the distal breakpoints further, D15S165, D15S1043, D15S1019, D15S976, D15S1031, D15S1010, D15S144, and D15S1048 have been examined in a subset of 15 PWS or AS patients for inclusion in deletions of this region. None showed evidence for uniparental inheritance of any of these markers, with the exception of one unusual deletion patient (PW-93) previously known to be deleted distally for D15S24, but also not carrying the same proximal breakpoint as common deletions ${ }^{1}$ (data not shown). The distal breakpoint in PW-93 occurred between D15S24, D15S1048 (both deleted) and D15S1031, D15S1043 (both heterozygous).

In contrast to the common PWS/AS deletion, duplications of the PWS/AS region frequently included markers distal to D15S12. One tandem duplication patient and two intrachromosomal triplication patients showed unequal intensities of the two amplified alleles at several loci, which is consistent with inclusion in the duplications (table 3). For many of the 12 inv dup 15q11-q13 patients examined, three distinct alleles were observed at distal loci, providing definitive proof of inclusion in the duplication. Interestingly, a minimum of four different breakpoints were observed in this region: (1) distal to D15S144, (2) between D15S1043 and D15S1010, (3) between D15S12 and D15S1019 (equivalent to the common deletion breakpoint), and (4) between GABRB3 and D15S12. Thus although inv dup 15 chromosomes can generally be distinguished as "large" (including the PWS/AS region) or "small" (excluding this region), there appears to be much more variability in breakpoint location than is seen among PWS/AS deletion patients.

\section{Discussion}

Unequal crossing over between homologous chromosomes at meiosis was excluded as the mechanism of 15q11-q13 deletion formation in four of six deletions of paternal origin. In contrast, all three informative AS cases showed evidence of recombination between markers flanking the deletion breakpoints, indicating an association with the deletion event. These results are opposite to those observed for HNPP deletions, where haplotype analysis showed the single maternal deletion case to be intrachromosomal in origin in contrast to recombination associated paternal deletions of the same region. ${ }^{27}$ Furthermore, the CMT1A duplications (which are duplications of the same region deleted in HNPP) are almost all paternal in origin, in contrast to $15 \mathrm{q} 11-\mathrm{q} 13$ duplications which are all maternal in origin. As deletion breakpoints do not appear to depend on parental origin in either case, the sex and region specific differences may simply reflect differences in the resolution of certain recombination intermediates rather than representing completely distinct mechanisms. Studies on the origin of the 7q11.23 deletion associated with Williams syndrome (WBS) showed evidence for a meiotic interchromosomal exchange between markers flanking the deletion in 22 of 27 cases. ${ }^{40} 41$ However, there was no apparent bias in parental origin of those WBS deletions which were associated with exchange.

Several hypotheses should be considered when considering the mechanism of microdeletion formation: (1) a premeiotic germline origin; (2) a meiotic event; or (3) an early somatic event.

(1) A premeiotic germline origin. Recurrence of an interstitial deletion from the same parent has never been reported for either PWS or AS (or any other interstitial microdeletion), making an early germline origin unlikely. A germline origin would also be likely to cause a paternal bias owing to increased cell divisions in spermatogenesis. However, the population frequency of maternal deletions ascertained through AS and paternal deletions ascertained through PWS are roughly equal (see introduction).

(2) A meiotic origin. Meiotic recombination in yeast is initiated by double strand breaks forming early in prophase. A chromosome instability leading to a high rate of nonhomologous recombination would probably also involve double strand breaks and be expected to show a high rate of homologous recombination at the same sites. Studies of unequal recombination between repeated genes in yeast show that those sequences involved in the highest rate of non-homologous (unequal) exchange also show high rates of homologous exchange. ${ }^{42}$ However, no excess of 
meiotic recombination is apparent at the PWS/AS deletion breakpoint sites, ${ }^{17} 18$ although the exact physical distance between D15S12 and D15S144 is not yet known. The observation that maternal and paternal deletions occur with equal frequency and involve the same breakpoint sites ${ }^{12}{ }^{13}$ is also apparently inconsistent with the striking sex specific differences in meiotic recombination in this region. ${ }^{18}$

The above arguments do not exclude a meiotic origin, only suggest that we may not completely understand the mechanism yet. There is evidence in yeast that exchange can occur during meiosis which is independent of exchange associated with functional chiasmata (see, for example, Hawley and $\mathrm{Arbel}^{43}$ ). Similarly, studies in Drosophila show evidence of recombination events owing to recombinatorial repair of transposon induced breaks. ${ }^{44}$ Perhaps the PWS/AS deletions are instead the result of an imperfect repair mechanism invoked to repair post-recombinational breaks that tend to occur within this region. The paternal intrachromosomal versus maternal interchromosomal difference could be the result of sex specific differences in use of sister chromatids versus homologous chromosomes for repair or of how the recombination-repair intermediate is resolved. However, because of the small number of informative cases, it is not yet possible to determine if the ratio of intra- to interchromosomal events is significantly different in PWS versus AS deletion cases.

If a classical meiotic unequal crossing over fully explained the occurrence of the maternal deletions, we might expect to observe reciprocal duplications of this region. Although maternal duplications of this region are commonly observed, an examination of distal breakpoints in interstitial duplications/ triplications of the commonly deleted PWS/AS region indicates a difference. The common deletion breakpoint occurs immediately distal to $\mathrm{D} 15 \mathrm{~S} 12^{9}$ and rarely includes $\mathrm{D} 15 \mathrm{~S} 24^{1{ }^{3}}$ (present results). A YAC contig of the PWS region shows that D15S24 lies on a YAC which does not overlap the YAC spanning the distal deletion breakpoint. ${ }^{9}$ D15S24 was, however, shown by FISH or molecular dosage analysis to be included in two duplication patients ${ }^{20}$ and three tandem triplication patients. ${ }^{22}$ In addition, results for one tandem duplication and two tandem triplication patients (including the case of Schinzel $e t a l^{3}$ ) presented here showed unequal intensities of the amplified alleles consistent with duplication of markers distal to the common deletion (table 2). Therefore, the duplicated region in all of seven duplication or triplication cases most probably extended further than the common deletion.

Furthermore, we were able to identify a minimum of four breakpoints among inv dup 15(q11-q13) chromosomes which included the PWS/AS critical regions, one of which corresponds to the common distal deletion breakpoint. Previous studies using FISH had identified only two of these breakpoints. ${ }^{33}$ Thus, although inv dup 15 chromosomes can generally be distinguished as "large" (including the
PWS/AS region) or "small" (excluding this region), there appears to be much more variability in breakpoint location than is seen among deletion patients. Perhaps the recombination events leading to duplication and deletions are the result of the same initiating mechanism, for example, a chromosome breakage, but the resolution as a duplication versus a deletion is influenced by which distal sequences are used for repair. As a series of repeated sequences at the proximal and distal breakpoint regions have been identified in this region, ${ }^{334} 46$ it may be that the location and orientation of specific repeats determines whether the recombination event will result in deletion, duplication, or inversion duplication.

(3) A post-meiotic origin. A post-meiotic origin also remains possible for at least some deletions and duplications. Mosaicism of 15q11-q13 deletions has been observed in association with hypomelanosis of Ito. ${ }^{47} 48$ The presence of mosaicism for 15q11-q13 deletions within PWS patients has also been suggested, ${ }^{6}{ }^{49}$ although these results suffer from methodological errors and are not convincing. However, observable mosaicism is not necessary to postulate a post-meiotic origin. A somatic origin of non-disjunction has been inferred in multiple instances of non-mosaic trisomy and uniparental disomy. ${ }^{50}{ }^{51}$ It has also been proven that post-meiotic events are common in the formation of homologous Robertsonian translocations and isochromosomes, despite the lack of any observed mosaicism, ${ }^{52}$ and has also been observed for de novo rearrangements ${ }^{53}$ including PWS/AS imprinting centre deletions. ${ }^{15}$ Furthermore, the maternal and paternal 15q11-q13 homologues appear to "pair" in late $S$ phase of the mitotic cell cycle in lymphocytes. ${ }^{39}$ The mechanism and function of this somatic "pairing" is unknown. However, it may provide a means to bring the two chromosomes 15 near enough to facilitate a mitotic recombination event.

Although there is an abundance of repetitive sequences in the human genome, recombination between repeats in non-homologous sites is not common. The observation of recurrent de novo deletions therefore implies several characteristics of chromatin at the breakpoint sites in addition to assuming that there exists some degree of homology between breakpoint sites. The proximal or distal deletion breakpoints or both must be sites prone to single or double strand breaks or otherwise susceptible to recombination/repair at some point in the cell or developmental cycle. The high rate of exchange between sequences 4-5 Mb apart also implies some physical proximity of these sequences in the nucleus, which can potentially be achieved simply by the nature of chromatin packaging in the region. Clearly more families need to be studied to determine if there is a parent of origin effect on the frequency of intra- versus interchromosomal involvement. Nonetheless, the initial observations indicate heterogeneity in the specific mechanism involved in the origin of $15 \mathrm{q} 11-\mathrm{q} 13$ rearrangements, including maternal and paternal deletions and maternal duplications, triplications, 
and inv dup 15q11-q13. Although a simple unequal crossing over mechanism may be involved, it is not sufficient to explain all the data. Further investigations including identification of repetitive sequences in the proximal and distal regions are needed to determine the exact cause of instability at the breakpoint sites.

We wish to thank the families and physicians for their cooperation in contributing blood samples to this study. This work was supported primarily by Swiss NF grant No 32-37798.93 (AS); part of this work was performed in 1988 by RDN in the laboratory of the late Professor S A Latt. RDN was supported by a research grant from March of Dimes Birth Defects Foundation.

1 Robinson WP, Bottani A, Yagang X, et al. Molecular, cytogenetic, and clinical investigations of Prader-Willi syndrome patients. Am ₹ Hum Genet 1991;49:1219-34.

2 Mascari MJ, Gottlieb W, Rogan PK, et al. The frequency of uniparental disomy in Prader-Willi syndrome. $N$ Engl $\mathcal{F}$ Med 1992;326:1599-607.

3 Zackowski JL, Nicholls RD, Gray BA, et al. Cytogenetic and molecular analysis in Angelman syndrome. Am $\mathcal{f} \mathrm{Med}$ Genet 1993;46:7-11.

4 Saitoh S, Harada N, Jinno Y, et al. Molecular and clinical study of 61 Angelman syndrome patients. Am $f$ Med Genet 1994;52:158-63.

5 Knoll JHM, Nicholls RD, Magenis RE, Graham JM, Lalande M, Latt SA. Angelman and Prader-Willi syn-
dromes share a common chromosome 15 deletion but difdromes share a common chromosome 15 deletion but differ in parental origin of the deletion. Am $\mathcal{F}$ Med Genet 1989; 32:285-90.

6 Cassidy SB, Thuline HC, Holm VA. Deletion of chromosome 15 (q11-13) in a Prader-Labhart-Willi syndrome clinic population. Am f Med Genet 1984;17:485-95.

7 Butler MG. Prader Willi syndrome: current understanding of cause and diagnosis. Am $\mathcal{F}$ Med Genet 1990;35:319-32.

8 Clayton-Smith J, Pembrey M. Angelman syndrome. $\mathcal{f} \mathrm{Med}$ Genet 1992;29:412-15.

9 Kuwano A, Mutirangura A, Dittrich B, et al. Molecular dissection of the Prader-Willi/Angelman syndrome region Genet 1992;1:417-25.

10 Nicholls RD. New insights reveal complex mechanisms in genomic imprinting. Am $\mathcal{F}$ Hum Genet 1994;54:733-40

11 Nicholls RD. Recombination model for generation of a submicroscopic deletion in familial Angelman syndrome. Hum Mol Genet 1994;3:9-11.

12 Knoll JHM, Nicholls RD, Magenis RD, et al. Angelman syndrome: three molecular classes identifed with chromosome 15q11-q13-specific DNA markers. Am $\mathcal{F}$ Hum Genet 1990;47:149-55.

13 Christian SL, Robinson WP, Huang B, et al. Molecular characterization of two proximal deletion breakpoint regions in both Prader-Willi and Angelman syndrome patients. Am $\mathcal{F}$ Hum Genet 1995;57:40-8.

14 Buiting K, Saitoh S, Gross S, et al. Inherited microdeletions in the Angelman and Prader-Willi syndromes define an imprinting centre on human chromosome 15. Nat Genet imprinting centre

15 Saitoh SB, Buiting K, Rogan PK, et al. Minimal definition of the imprinting center and fixation of a chromosome 15q-q13 epigenotype by imprinting mutations. Proc Natl Acad Sci USA 1996;93:7811-15.

16 Nicholls RD, Fischel-Ghodsian N, Higgs DR. Recombination at the human alpha-globin gene cluster: sequence features and topological constraints. Cell 1987;49:369-78.

17 Robinson WP, Spiegel R, Schinzel AA. Deletion breakpoints associated with the Prader-Willi and Angelman syndromes (15q11-q13) are not sites of high homologous recombination. Hum Genet 1993;91:181-4.

18 Robinson WP, Lalande M. Sex-specific meiotic recombination in the Prader-Willi/Angelman syndrome imprinted region. Hum Mol Genet 1995;4:801-6.

19 Clayton-Smith J, Webb T, Cheng XJ, Pembrey ME, Malcolm SE. Duplication of chromosome 15 in the region 15q11-13 in a patient with developmental delay and ataxia $15 \mathrm{q} 11-13$ in a patient with developmental delay and ataxia
with similarities to Angelman syndrome. $f \mathrm{Med}$ Genet with similarities

20 Mutirangura A, Kuwano A, Robinson WP, Greenberg F, Malcolm S, Ledbetter DH. Duplication of chromosome 15q Prader-Willi and Angelman syndromes: a gene dosage paradox. Am f Hum Genet 1993;53:A584.

21 Abeliovich D, Dagan J, Werner M, Lerer I, Shapira Y, Meiner V. Simultaneous formation of inv $\operatorname{dup}(15)$ and dup $(15 q)$ in a girl with developmental delay: origin of the abnormal chromosomes. Eur f Hum Genet 1995;3:49-55.

22 Holowinsky S, Black SH, Howard-Peebles PN, et al. Triplication 15q11-13 in two unrelated patients with hypotonia, cognitive delays and visual impairment. Am $₹$ Hum Genet 1993;53:A125.

23 Schinzel AA, Brecevic L, Bernasconi F, et al. Intrachromosomal triplication of 15q11-q13. F Med Genet 1994;31:798803.

24 Cassidy SB, Conroy J, Schwartz S. A paternal intrachromosomal triplication in a hypotonic, developmentally delayed child without Prader-W

25 Pentao L, Wise CA, Chinault AC, Patel PI, Lupski JR. Charcot-Marie-Tooth type IA duplication appears to arise from recombination at repeat sequences flanking the 1.5 Mb monomer unit. Nat Genet 1992;2:292-300.

26 Chance PF, Abbas N, Lensch MN, et al. Two autosomal dominant neuropathies result from reciprocal DNA dominant neuropathies result from reciprocal DNA duplication/deletion of a

27 LeGuern E, Gouider R, Ravisé N, et al. A de novo case of hereditary neuropathy with liability to pressure palsies (HNPP) of maternal origin: a new mechanism for deletion in 17p11.2? Hum Mol Genet 1996;5:103-6.

28 Blair IP, Nash J, Gordin M, Nicholson GA. Prevalence and origin of de novo duplications in Charcot-Marie-Tooth disease type 1A: first report of a de novo duplication with a maternal origin. Am f Hum Genet 1996;58:472-6.

29 Palau F, Lofgren A, De Jonghe $P$, et al. Origin of de novo duplication in Charcot-Marie-Tooth disease type 1A: unequal non-sister chromatid exchange during spermatogenesis. Hum Mol Genet 1993;2:2031-5.

30 Reiter LT, Murakami T, Koeuth T, et al. A recombination hotspot responsible for two inherited peripheral neuropathies is located near a mariner transposon-like element. Nat Genet 1996;12:288-97.

31 Cheng SD, Spinner N, Zackai E Knoll J. Cytogenetic and molecular characterization of inverted duplicated chromosomes 15 from 11 patients. Am $\mathcal{F}$ Hum Genet 1994;55:7539.

32 Leana-Cox J, Jenkins L, Palmer C, et al. Molecular cytogenetic analysis of inv dup(15) chromosomes using probes specific for the Prader-Will/Angelman syndrome region
clinical implications. Am ₹ Hum Genet 1994;54:748-56.

33 Robinson WP, Horsthemke B, Leonard S, et al. Report of the third international workshop on chromosome 15 mapping 1996. Cytogenet Cell Genet (in press).

34 Van Dyke DL, Babu VR, Weiss L. Parental age, and how extra isochromosomes (secondary trisomy) arise. Clin Genet 1987;32:75-80.

35 Spinner NB, Zackai E, Cheng SD, Knoll JH. Supernumerary inv dup (15) in a patient with Angelman syndrome and a deletion of 15q11-q13. Am ₹ Med Genet 1995;57:61-5.

6 Tantravahi UN, Nicholls RD, Stroh $\mathrm{H}$, et al. Quantitative calibration and use of DNA probes for investigating chromosome abnormalities in the Prader-Willi syndrome. Am $\mathcal{F}$ Med Genet 1989;33:78-87.

37 Nicholls RD, Knoll JH, Glatt K, et al. Restriction fragment length polymorphisms within proximal $15 \mathrm{q}$ and their use in molecular cytogenetics and the Prader-Willi syndrome. Am f Med Genet 1989;33:66-77.

38 Hulten MA, Hall JC. Proposed meiotic mechanism of genomic imprinting. Chromosomes Today 1989;10:157-62.

39 LaSalle JM, Lalande M. Homologous association of oppositely imprinted chromosomal domains. Science 1996;

40 Dutly F, Schinzel A. Unequal interchromosomal rearrangements may result in elastin gene deletions causing the
Williams-Beuren syndrome. Hum Mol Genet 1996;5:18938 .

41 Urban Z, Helms C, Fekete G, et al. 7q11.23 deletions in Williams syndrome arise as a consequence of unequal meiotic crossover. Am f Hum Genet 1996;59:958-62.

42 Haber JE, Leung WY, Borts RH, Lichten $M$. The frequency of meiotic recombination in yeast is independent of the number and position of homologous donor sequences: implications for chromosome pairing. Proc Natl Acad Sci USA 1991;88:1120-4.

43 Hawley RS, Arbel T. Yeast genetics and the fall of the classical view of meiosis. Cell 1993;72:301-3.

44 Hawley RS, Frazier JA, Rasooly R. Commentary. Separation anxiety: the etiology of nondisjunction in flies and people. Hum Mol Genet 1994;3:1521-8.

45 Buiting K, Greger V, Brownstein $\mathrm{BH}$, et al. A putative gene family in 15q11-13 and 16p11.2: possible implications for Prader-Willi and Angelman syndromes. Proc Natl Acad Sci USA 1992;89:5457-61.

46 Amos-Landgraf J, Gottlieb W, Rogan PK, Nicholls RD. Chromosome breakage in Prader-Willi and Angelman syndrome deletions may involve recombination between a repeat at the proximal and distal breakpoints. Am $\mathcal{F ~ H u m}$ Genet Suppl 1994;55:A38.

47 Turleau C, Taillard F, Doussau de Bazignan M, Delephine N, Desbois JC, de Grouchy J. Hypomelanosis of Ito (incotinentia pigmenti achromians) and mosaicism for a microdeletion of 15q1. Hum Genet 1986;74:185-7.

48 Pellegrino JE, Schnur RE, Kline R, Zackai EH, Spinner NB. Pellegrino JE, Schnur RE, Kline R, Zackai EH, Spinner NB.
Mosaic loss of $15 \mathrm{q} 11 \mathrm{q} 13$ with hypomelanosis of Ito: is Mosaic loss of $15 \mathrm{q} 11 \mathrm{q} 13$ with hypomelanosis of Ito:
there a role for the P gene? Hum Genet 1995;96:485-9.

49 Mowery-Rushton PA, Hanchett JM, Zipf WB, Rogan PK, Surti U. Identification of Prader-Willi syndrome mosaicism by fluorescent in situ hybridization. Am $\mathcal{F}$ Med Genet 1996;
66:403-12.

50 Antonarakis SE, Avramopoulos D, Blouin JL, Talbot CC, Schinzel AA. Mitotic (somatic cell) errors cause trisomy 21 in about $4.5 \%$ of cases and are not associated with advanced maternal age. Nat Genet 1993;3:146-50.

51 Robinson WP, Bernasconi F, Mutirangura A, et al. Nondisjunction of chromosome 15: origin and recombination. Am f Hum Genet 1993;53:740-51.

52 Robinson WP Bernasconi F, Basaran S, et al. A somatic origin of homologous Robertsonian translocations and isochromosomes. Am $\mathcal{F}$ Hum Genet 1994;54:290-302.

53 Schinzel AA, Kotzot D, Brecevic L, et al. Maternal heterodisomy (16)(p13.1-qter) and mosaicism between maternal heterodisomy and trisomy for (16)(pter-p13.1) in a 2 year old short and retarded boy with multiple anomalies. Eur $\mathcal{f}$ Hum Genet (in press). 